\title{
NDVI Variation and Its Responses to Climate Change on the Northern Loess Plateau of China from 1998 to 2012
}

\author{
Tingting Ning, ${ }^{1,2}$ Wenzhao Liu, ${ }^{1}$ Wen Lin, ${ }^{1,2}$ and Xiaoqiang Song ${ }^{3}$ \\ ${ }^{1}$ State Key Laboratory of Soil Erosion and Dryland Farming on the Loess Plateau, Institute of Soil and Water Conservation, \\ Chinese Academy of Sciences and Ministry of Water Resources, Yangling, Shaanxi 712100, China \\ ${ }^{2}$ University of the Chinese Academy of Sciences, Beijing 100049, China \\ ${ }^{3}$ Soil and Water Conservation Bureau of Shaanxi Province, Xian, Shaanxi 710004, China
}

Correspondence should be addressed to Wenzhao Liu; wzliu@ms.iswc.ac.cn

Received 30 January 2015; Revised 23 April 2015; Accepted 30 April 2015

Academic Editor: Steffen Mischke

Copyright (C) 2015 Tingting Ning et al. This is an open access article distributed under the Creative Commons Attribution License, which permits unrestricted use, distribution, and reproduction in any medium, provided the original work is properly cited.

\begin{abstract}
This study analyzed temporal and spatial changes of normalized difference vegetation index (NDVI) on the northern Loess Plateau and their correlation with climatic factors from 1998 to 2012. The possible impacts of human activities on the NDVI changes were also explored. The results showed that (1) the annual maximum NDVI showed an upward trend. The significantly increased NDVI and decreasing severe desertification areas demonstrate that the vegetation condition improved in this area. (2) Over the past decades, climate tended to be warmer and drier. However, the mean temperature significantly decreased and precipitation slightly increased from 1998 to 2012, especially in spring and summer, which was one of the major reasons for the increase in the annual maximum NDVI. Compared to temperature, vegetation was more sensitive to precipitation changes in this area. The NDVI and annual precipitation changes were highly synchronous over the first half of the year, while a 1-month time lag existed between the two variables during the second half of the year. (3) Positive human activities, including the "Grain for Green" program and successful environmental treatments at coal mining bases, were some of the other factors that improved the vegetation condition.
\end{abstract}

\section{Introduction}

Vegetation is the main component of terrestrial ecosystems on earth and plays an important role in the water, energy exchange, and biogeochemical cycles on terrestrial surfaces [1]. Linking soil, atmosphere, and moisture [2, 3], vegetation plays an irreplaceable role in maintaining climate stability, regulating the carbon balance, and reducing global-scale greenhouse gases [4]. However, vegetation is sensitive to climate changes. Vegetation dynamics and the responses to climate changes have been recognized as one of the core issues of global change in terrestrial ecosystems [5].

Due to high spatial and temporal resolutions and accuracy, remotely sensed data can provide technical support for monitoring vegetation dynamics at large scales. The normalized difference vegetation index (NDVI) was proposed by Rouse et al. based on red and near-infrared reflectance [6]. The NDVI has been frequently used for studying vegetation dynamics because it is highly correlated with the photosynthetic capacity, the leaf area index, biomass, and net primary productivity [7]. The NDVI ranges from -1 to 1 . Higher positive NDVI values correspond to higher vegetation coverage and activity [8]. Negative NDVI values indicate the presence of clouds, snow, water, or a bright, nonvegetated surface [9]. Moreover, the NDVI has been widely used to assess the net primary productivity of vegetation (NPP) [10, $11]$ and crop production $[12,13]$ and to indicate the feedback effects of vegetation on local climates [14-16]. In addition, the NDVI has also been used to improve predictions and impact assessments related to disturbances, such as droughts [17] and floods [18].

Over the past 20 years, many scholars have conducted extensive research regarding surface vegetation coverage at different spatial and temporal scales based on NDVI time series data. Their research has shown that global vegetation activity has been gradually increasing, especially in northern middle-high latitude regions [19-21]. And similar results have been observed on the Tibet Plateau [22], the Loess 
Plateau [23, 24] and over southwestern [25], central, and northwestern China [4, 26]. Conversely, decreasing NDVI trends have been detected in many regions, such as in the southwestern United States [27], northeastern Thailand [28], the upper catchments of the Yellow River [29], and the Lancang River source region [30].

In addition, the relationship between the NDVI and climatic factors has been explored by scholars at both local and regional scales since the 1980s. However, the mechanisms of the vegetative response to climate change are uncertain [31], and the results from previous studies have varied due to different vegetation characteristics, regions, and study methods. For example, Schultz and Halpert found that the global-scale NDVI data are not highly correlated with precipitation, although they did not correlate the data with temperature [32]. Liu et al. reported that vegetation coverage in the arid, western regions of northeastern Asia exhibits a strongly positive correlation with precipitation, while spatial changes in the NDVI, which are influenced by temperature in the region, are less pronounced [33]. He et al. examined the seasonal and inter-annual relationships between vegetation and climate data from 1985 to 2007 over Canadian ecosystems. Their results suggested that the relationship between the NDVI and temperature is stronger than that with precipitation [34]. Clearly, the key climate factors impacting the NDVI vary by region. Therefore, it is essential to conduct regional-scale research.

The northern Loess Plateau (Figure 1), which is located in the middle reach of the Yellow River, has a semiarid climate with an annual mean precipitation of 300 to $500 \mathrm{~mm}$ and an annual mean temperature of $6-9^{\circ} \mathrm{C}$. This region is subject to soil erosion; numerous soil conservation measures have been implemented. Moreover, it is the largest coal mining region in China, with coal reserves accounting for $60 \%$ of the national total [35]. Both erosion and mining, which can be linked to human activities, have seriously altered surface conditions. Therefore, due to the combined impacts of climate change and human activities, it has become necessary to study the vegetation condition changes in this area in recent years. Based on the SPOT-VEGETATION DN, precipitation, and temperature data, this study investigated the spatial and temporal changes of the NDVI, precipitation and temperature over the past 15 years. We also explored the relationship between the NDVI and climate factors. Finally, based on two land-use maps, we analyzed the possible influence of human activities on the NDVI. This information can be useful when assessing the effects of ecological construction and for providing a scientific basis for corresponding policies.

\section{Data and Methods}

2.1. Dataset. The data used in this study were as follows:

(1) NDVI data from 1998 to 2012 were obtained from SPOT-4 VGT-DN. The SPOT-4 satellite was launched in March 1998, having 10-day composite temporal resolution and $1-\mathrm{km}^{2}$ spatial resolution. The stretched values range from 0 to 255 . The true NDVI values were restored with the following equation, which was

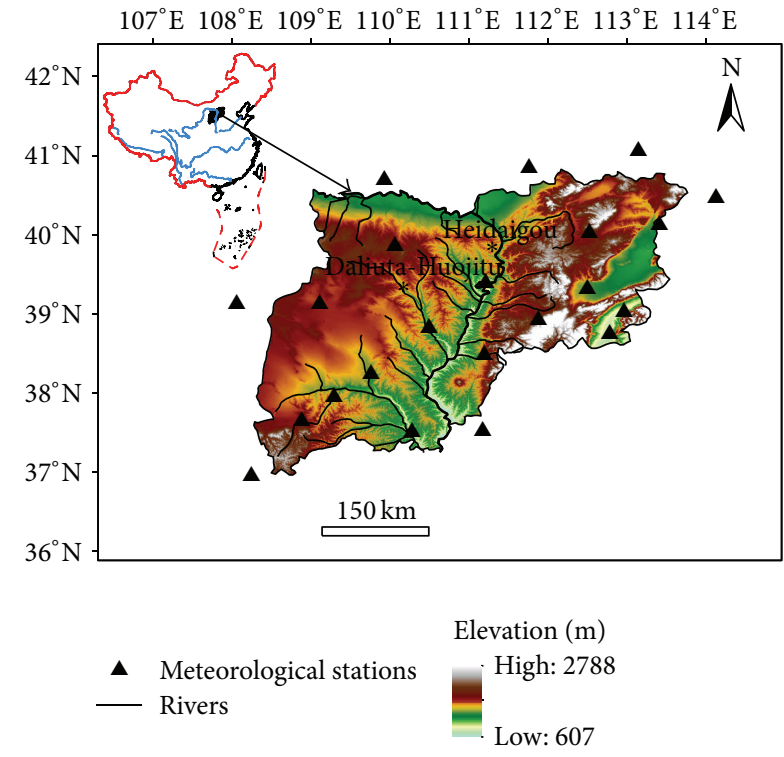

FIGURE 1: Location of the study area.

developed by the image processing and archiving center, VITO, Belgium (http://www.vgt.vito.be/):

$$
\mathrm{NDVI}=\mathrm{DN} \times 0.004-0.1,
$$

where $\mathrm{DN}$ is the digital count number used for storage.

(2) Monthly precipitation and temperature from 22 weather stations were obtained from the China Meteorological Administration for the period of 1957 to 2012 and has been carried out quality control. A few missing data were interpolated based on values from neighboring stations over the same period. The IDW (Inverse Distance Weighted) interpolation method was used to interpret the spatial distribution of monthly and annual precipitation and temperature.

(3) Two land-use maps (i.e., from 1997 and 2010) were used in this study. They were produced from Landsat Thematic Mapper (TM) images using the visual interpretation method. During the interpretation process, the practical field survey was considered, and landuse styles were classified into multiple categories, including farmland, forestland, grassland, water bodies, urban and built-up land, and unused land.

We also selected Heidaigou $\left(111.22^{\circ} \mathrm{E}-111.33^{\circ} \mathrm{E}, 39.72^{\circ} \mathrm{N}-\right.$ $\left.39.82^{\circ} \mathrm{N}\right)$ and Daliuta-Huojitu $\left(110.05^{\circ} \mathrm{E}-110.12^{\circ} \mathrm{E}, 39.17^{\circ} \mathrm{N}-\right.$ $\left.39.37^{\circ} \mathrm{N}\right)$, which represent the largest opencast mine and well mine bases in this area, respectively, to analyze their temporal NDVI variations as compared with those for the entire study area.

\subsection{Methods}

2.2.1. Monthly and Annual NDVI. The maximum value compositing (MVC) procedure, as described by Holben [36], was 
used to merge NDVI values from 10 consecutive days to produce NDVI values for each month and year. The MVC method was found to be a reliable procedure for detecting changes in vegetation coverage and has been widely used to obtain monthly and annual NDVI values [37-40].

2.2.2. Calculation of NDVI Trends. To further investigate the yearly maximum NDVI trends, linear trends were examined on a perpixel basis from 1998 to 2012 . This calculation is as follows:

$$
\theta_{\text {slope }}=\frac{n \times \sum_{i=1}^{n} i \times \mathrm{NDVI}_{i}-\sum_{i=1}^{n} i \sum_{i=1}^{n} \mathrm{NDVI}_{i}}{n \times \sum_{i=1}^{n} i^{2}-\left(\sum_{i=1}^{n} i\right)^{2}},
$$

where $n$ represents the number of study years and $\mathrm{NDVI}_{i}$ is the maximum NDVI in the $i$ th year. $\theta_{\text {slope }}>0$ means that the NDVI over $n$ years increased. The opposite relationship signifies a decreasing trend. The $F$ test was used to examine the significance of these trends. Depending on the significance level of a given pixel, it was filtered into one of five classes: extremely significant increase (ESI) or decrease (ESD) $(P<0.01)$, significant increase $(\mathrm{SI})$ or decrease $(\mathrm{SD})(0.01<$ $P<0.05)$, or no significant change (NSC) $(P>0.05)$.

2.2.3. Classification of Desertification Land. Previous research has shown that there is a linear relation between vegetation indices (e.g., the NDVI) and vegetation coverage. Therefore, the NDVI can be converted into vegetation coverage. Then, the study area, which has various vegetation coverages, can be classified according to desertification grading standards [41].

2.2.4. Partial Correlation Analysis Model. A coefficient of partial correlation is determined based on the simple correlation coefficient. The partial correlation coefficient of the NDVI and temperature or precipitation is defined as follows:

$$
R_{x y \cdot z}=\frac{R_{x y}-R_{x z} R_{y z}}{\sqrt{\left(1-R_{x z}^{2}\right)\left(1-R_{y z}^{2}\right)}},
$$

where $R_{x y \cdot z}$ is the partial correlation coefficient between variables $x$ and $y$ when $z$ is constant. Moreover, $R_{x y}, R_{x z}$, and $R_{y z}$ represent the simple correlation coefficients between variables $x$ and $y, y$ and $z$, and $x$ and $z$, respectively.

\section{Results and Discussion}

\subsection{Temporal and Spatial Variation Characteristics of the NDVI}

3.1.1. Spatial Distribution of the Annual Maximum NDVI. The spatial distribution of the annual maximum NDVI in the study area is shown in Figure 2(a). The NDVI gradually decreased from east to west, exhibiting evident spatial heterogeneities. For the entire region, the mean annual maximum NDVI from 1998 to 2012 was 0.44 , ranging from 0.07 to 0.82 . For the Heidaigou and Daliuta-Huojitu coal mining areas, the annual maximum NDVI values over the 15 -year study period were 0.36 and 0.38 , respectively. The greatest NDVI values were located in mountainous and hilly regions in the southeastern portion of the study area. The sparse deciduous broad-leaved forest, including Pinus tabulaeformis, Poplarbirch, and Larix principis-rupprechtii, and secondary shrubgrassland are the dominant vegetation types. The lowest NDVI values were found in Jungar Banner, Ejin Horo Banner, and Wushen Banner in Inner Mongolia, as well as northern portions of Shaanxi province. Most areas of the northern Loess Plateau are typical semiarid temperate steppe areas, where the dominant vegetation can be characterized as shrub and semiarid herb; the main plant communities include the Stipa plant community, Thymus serpyllum community, Caragana community, Sabina vulgaris community, and Artemisia ordosica community.

3.1.2. Temporal and Spatial Variation of the NDVI. From 1998 to 2012, the NDVI exhibited an increasing trend in the study area, with a rate of increase of 0.09 per decade (Figure 2(b)). The annual maximum NDVI at the Heidaigou mining base exhibited an upward trend at a rate of 0.03 per decade, which was slower than the trend for the entire study area. The Daliuta-Huojitu coal mining base exhibited a trend of 0.12 per decade, which increased faster than the trend for the entire study area. The significance level for the NDVI trend is shown in Figure 2(c). Over the entire region, the areas where the NDVI exhibited ESI and SI trends accounted for $56.4 \%$ and $17.2 \%$ of the total area, respectively. Meanwhile, the areas where the NDVI exhibited NSC trends accounted for $26 \%$ of the total area, and the percentage of areas with SC and ESC trends was very small (less than $1 \%$ ). At the Heidaigou mining base, the percentages of the area characterized as SI and ESI were only $17.4 \%$ and $9 \%$, respectively, while NSC accounted for $50 \%$ of the area. At the Daliuta-Huojitu mining base, the vegetation coverage was found to be more abundant, and more than $95 \%$ of this area was classified as ESC.

Spatially (Figure 2(c)), the areas where the NDVI exhibited ESI trends from 1998 to 2012 were primarily distributed in northern Shaanxi province and the southeast edge of Mu Us Sandy Land. Areas where the NDVI exhibited SD trends were primarily located near Xingxian and Wuzhai in Shanxi and parts of Jungar Banner in Inner Mongolia. The areas where the NDVI exhibited NSC trends were primarily distributed near Youyu and Datong in Shanxi, and Liangcheng, Lingle, and the Qingshui River in Inner Mongolia. Furthermore, the annual maximum NDVI time series in the study area from 1998 to 2012 can be divided into three periods (Figure $2(\mathrm{~d})$ ). The regional average NDVI decreased from 1998 to 2001, then increased continuously from 2002 to 2008, and increased again from 2009 to 2012, although significant fluctuations were observed during this time period. The NDVI values at Heidaigou and Daliuta-Huojitu also exhibited similar three-stage variations, although the values were lower than the area average over the past 15-year period. The greatest annual NDVI occurred in 2012 for both the entire study area and the two coal mining areas. Moreover, excluding the period from 1998 to 2001, the NDVI at Daliuta-Huojitu was higher than that at Heidaigou. 

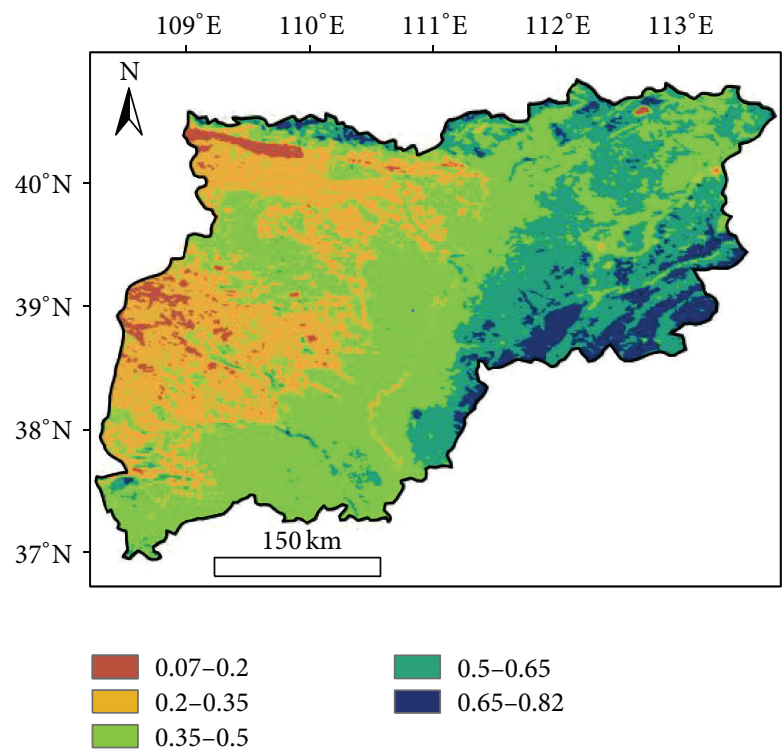

(a)
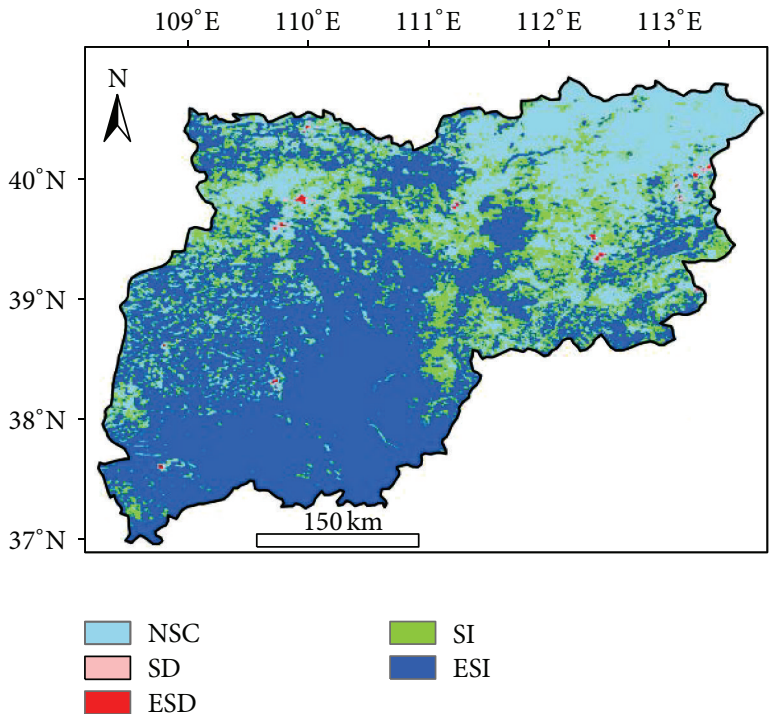

(c)
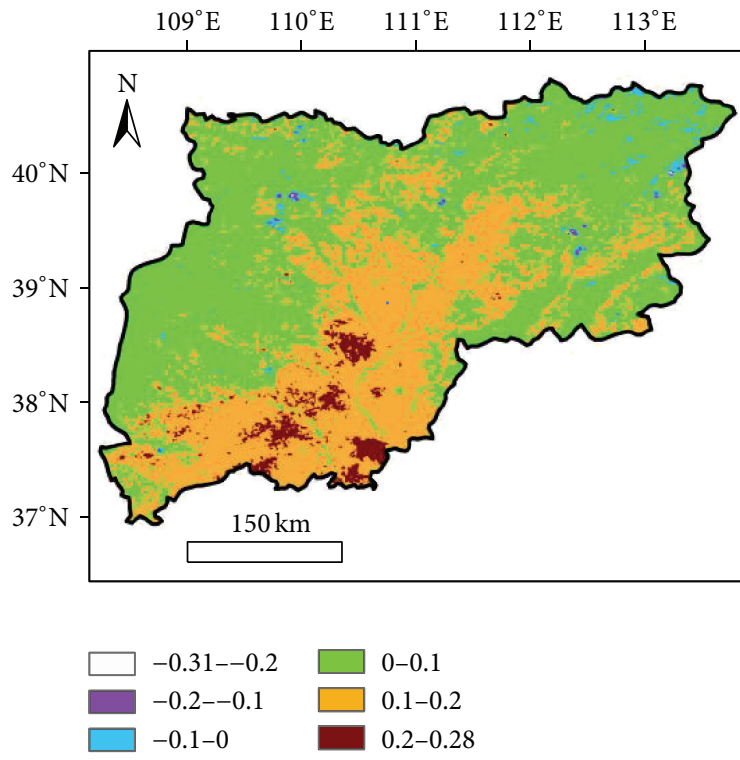

(b)

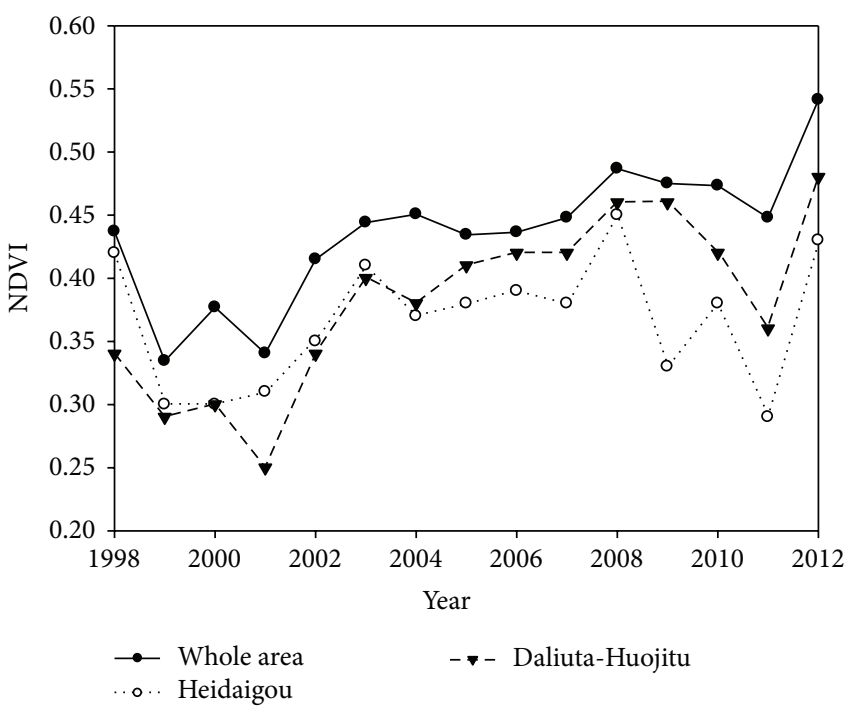

(d)

Figure 2: (a) The spatial distribution of the annual maximum NDVI; (b) the NDVI trends; (c) the significance level of the NDVI trends; and (d) the interannual NDVI changes for the northern Loess Plateau from 1998 to 2012.

3.1.3. The Dynamic Change of Desertification Land. According to the relationship between the NDVI and vegetation coverage [41], the study area can be divided into 5 grades, including slight, light, moderate, severe, and extremely severe desertification (Table 1). The proportional changes of land area for the different types of desertification are shown in Figure 3. Most areas in this region were characterized as exhibiting moderate and light desertification, accounting for $39.7 \%$ and $30.6 \%$ of the entire area, respectively. Areas of extremely severe and slight desertification were smaller, accounting for only $2.4 \%$ and $0.7 \%$ of the entire area, respectively.
Over the 15-year study period, extremely severe, moderate, and slight desertification areas slightly changed, while severe and light desertification areas significantly changed. Meanwhile, severe desertification areas decreased significantly $(P<0.05)$ from $54.7 \%$ in 1999 to $8.9 \%$ in 2012, which is an average of $2.1 \% / y r$. Light desertification areas increased significantly $(P<0.01)$ from $36.7 \%$ in 1998 to $61 \%$ in 2012 , which is an average of $2.2 \% / y r$. At the Heidaigou and Daliuta-Huojitu coal mining locations, most areas were considered moderate desertification, accounting for $70.8 \%$ and $92.0 \%$ of the entire study area, respectively. 
TABLE 1: Gradation standard for land desertification.

\begin{tabular}{lcc}
\hline Desertification grade & Vegetation coverage & NDVI \\
\hline Extremely severe & $<0.1$ & $<0.19$ \\
Severe & $0.1-0.3$ & $0.19-0.34$ \\
Moderate & $0.3-0.5$ & $0.34-0.51$ \\
Light & $0.5-0.7$ & $0.51-0.78$ \\
Slight & $>0.7$ & $0.78-0.83$ \\
\hline
\end{tabular}

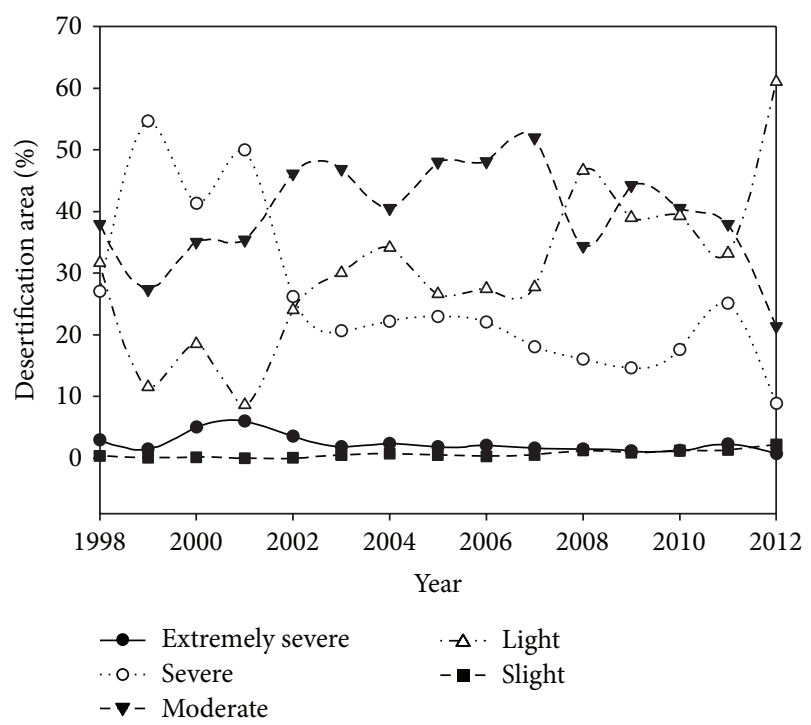

Figure 3: The proportional changes of land area for the different types of desertification on the northern Loess Plateau from 1998 to 2012.

\subsection{Relationship between the NDVI and Climatic Factors}

3.2.1. Annual Correlations between the NDVI and Climate. From 1957 to 2012, the annual mean temperature (TEM) significantly increased over the entire study area at a rate of $0.24^{\circ} \mathrm{C} / 10 \mathrm{yr}(P<0.05)$ (Figure $\left.4(\mathrm{a})\right)$. The annual precipitation (PRE) slightly decreased, at a rate of $9.16 \mathrm{~mm} / 10 \mathrm{yr}$ (Figure 4(b)). These rates indicate that a warming and drying trend occurred during the 56-year period. However, from 1998 to 2012 , the average TEM of the study area was $8.8^{\circ} \mathrm{C}$ and exhibited a significant downward trend at the rate of $-0.61^{\circ} \mathrm{C} / 10 \mathrm{yr}(P<0.05)$. The TEM gradually decreased from the southwest to the northeast. The lowest TEM was located in the northeast region, with an annual average of less than $7^{\circ} \mathrm{C}$, while the highest TEM was located in the southwest, with an annual average exceeding $10^{\circ} \mathrm{C}$ (Figure $4(\mathrm{c})$ ). On an interannual time scale, the partial correlation coefficient of the NDVI and the TEM for the entire region was -0.29 . The areal percentage of the regions where the NDVI exhibited a negative correlation with the TEM was $86.62 \%(11.78 \%$, $P<0.05 ; 72.47 \%, P<0.01)$. These areas were primarily located in the western and southern regions of the study area. The areal percentage of the regions where a significantly positive correlation existed between the NDVI and the TEM was less than $1 \%$; these areas were primarily distributed in the northeast (Figure 5(a)).
From 1998 to 2012, the mean annual PRE for the region was $387.2 \mathrm{~mm}$ and it exhibited insignificant increasing trend at a rate of $52 \mathrm{~mm} / 10 \mathrm{yr}(P>0.05)$. As shown in Figure $4(\mathrm{~d})$, the PRE gradually decreased from the southeast to northwest; the smallest PRE was measured in the northwest, with an annual average of less than $360 \mathrm{~mm}$. The greatest PRE was measured in the southeast, with an annual average of more than $420 \mathrm{~mm}$. The partial correlation coefficient of the NDVI and the PRE for the entire region was 0.51. The areal percentage of the regions where the NDVI exhibited a positive correlation with the PRE was 99.33\% (30.04\%, $P<0.05 ; 20.12 \%, P<0.01)$, and the correlation coefficient between the NDVI and the PRE exhibited a strong increasing trend from the southwest to the northeast (Figure 5(b)). On the northern Loess Plateau, the correlation with the annual NDVI was stronger for precipitation than for temperature over the 15-year period. This finding can be explained by the fact that the study area is primarily located in arid and semiarid climate regimes, where precipitation is the limiting factor for vegetation growth and vegetation is more sensitive to precipitation changes. In general, higher temperatures will accelerate the evaporation process, which results in water scarcity and prohibits vegetation growth [42]. However, there was a significant decrease in temperature and a weak increase in precipitation in the study area from 1998 to 2012. These trends are good for vegetation growth and represent one of the major reasons for the increase in the annual NDVI.

\subsubsection{Monthly Relationship between the NDVI and Climate.} The maximum monthly NDVI over the 15 -year study period was observed on the northern Loess Plateau in August, which was largely controlled by the hydrothermal conditions during this period (Figure 6). Most areas of the northern Loess Plateau are considered to have a temperate continental grassland climate. In the summer (June to August), the climate is governed by marine air masses and prevailing easterly and southeasterly winds, which are characterized by high temperatures and copious rainfall. Approximately two-thirds of the annual precipitation is concentrated in the summer, which benefits vegetation growth. Furthermore, spring precipitation also increased at a rate of $2.45 \mathrm{~mm} / 10 \mathrm{yr}$ from 1998 to 2012, which is important for the accumulation of biomass production.

The effect of climatic factors on the NDVI may differ according to the growth phase [43]. Therefore, we performed partial correlation analyses for the monthly NDVI, temperature, and precipitation to determine the monthly and seasonal differences (Figure 7). The average correlation between the monthly NDVI and the TEM across the study area was -0.14 , which was weaker than that for an interannual time scale $(-0.29)$ (Figure $7(\mathrm{a})$ ). The areal percentage of the regions where the NDVI exhibited a negative correlation with the TEM was $58.32 \%$. The percentage of significantly positive correlated areas did not exceed $1 \%$, which was substantially less than that for an interannual time scale. In contrast, the correlation between the monthly NDVI and PRE was stronger than that for an interannual time scale (Figure 7(b)). For the study area average, the correlation coefficient was 


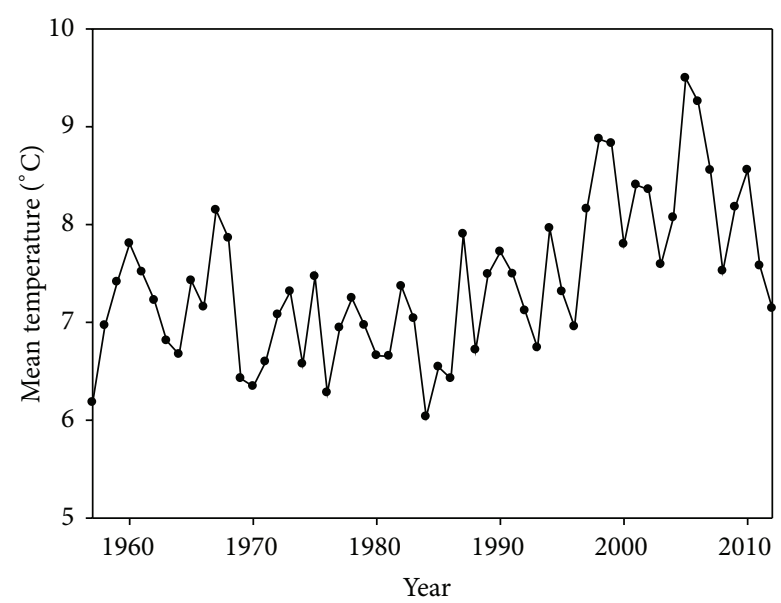

(a)
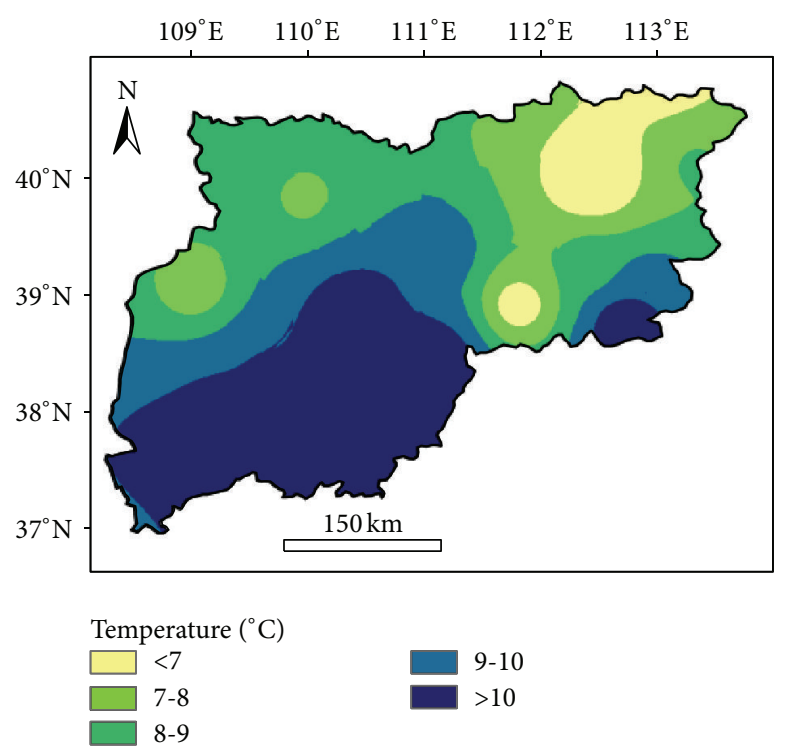

(c)

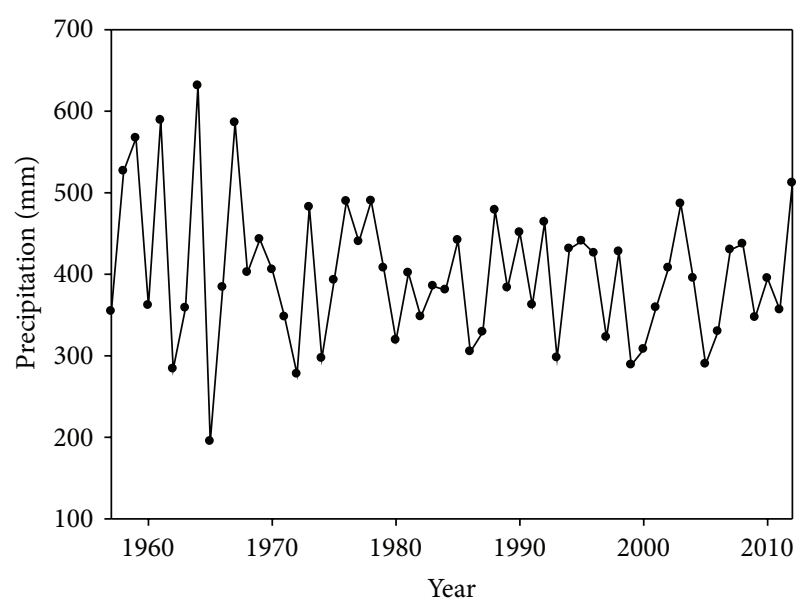

(b)

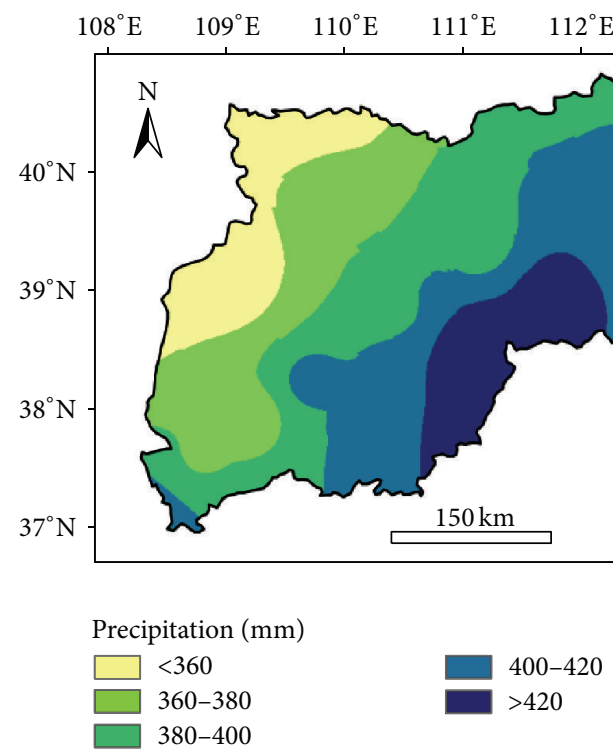

(d)

FIGURE 4: The temporal variation of interannual (a) temperature and (b) precipitation from 1957 to 2012; spatial change in the (c) annual mean temperature and (d) annual precipitation on the northern Loess Plateau from 1998 to 2012.

0.78 , and the areal percentage of the regions where the NDVI exhibited a positive correlation with the PRE was $99.99 \%$ (41.28\%, $P<0.05 ; 55.26 \%, P<0.01)$. These results further suggest that the PRE was the dominant factor controlling plant growth because it was very sensitive to PRE changes.

\subsubsection{Time Lag Effect of NDVI-PRE Relationship. According} to Figure 6, the NDVI and the PRE exhibited similar temporal variations during the first half of the year. While in the latter half of the year, the NDVI response to the PRE exhibited a 1month time lag. To further examine the synchrony and timelag effects of the PRE and NDVI dynamics, we calculated the partial correlation coefficient between the NDVI and the PRE for the same month in the first half and the last half of the year and the NDVI for a particular month and the PRE for the preceding month in the last half of the year, respectively. The results showed that in the first half of the year, the average correlation between the NDVI and the PRE over the study area for the same month was 0.90 , and the areal percentage of the areas where the NDVI exhibited a significantly positive correlation with the PRE exceeded $55 \%$ of total study area $(P<0.05)$. This finding suggests that the NDVI was sensitive to the PRE of the same month in this period, which is similar to the results shown in Figure 6. Because the PRE in this period was small, the precipitation could be fully utilized by plants and converted to biomass production over short time periods.

The correlation between the NDVI of a particular month and the PRE of the preceding month in the last half of the year was 0.43 , which was greater than that between the NDVI and the PRE for the same month in this period (0.33). The areal percentage of significantly positive correlated areas also increased $(P<0.05)$, demonstrating that a 1-month lag time existed between the NDVI and the PRE during the last half 


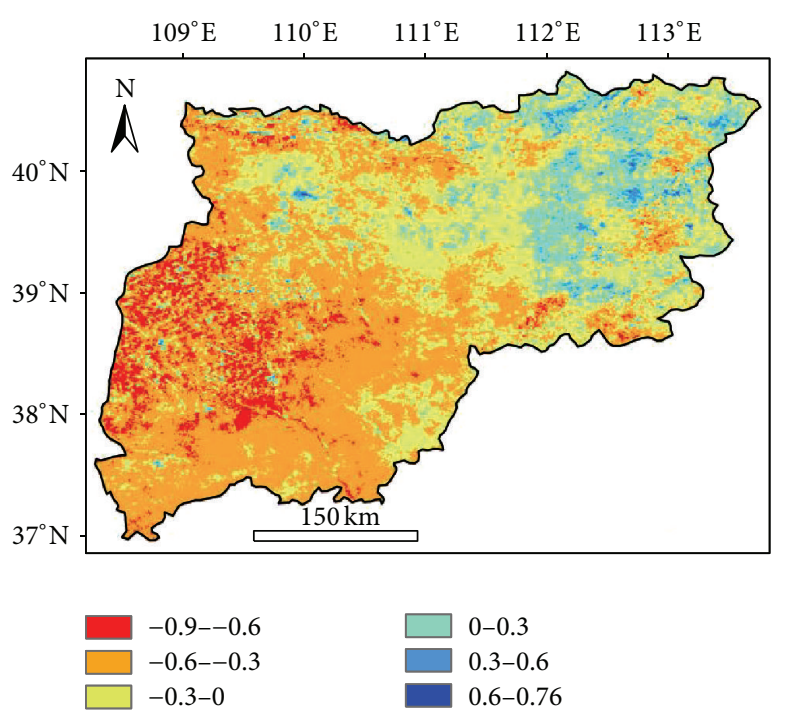

(a)

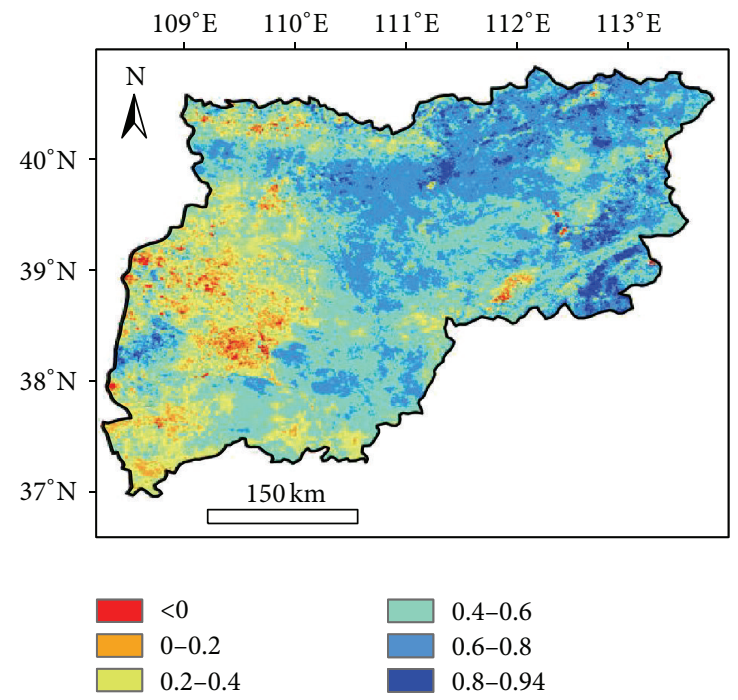

(b)

FIGURE 5: Correlation between the annual NDVI and annual (a) mean temperature and (b) precipitation on the northern Loess Plateau from 1998 to 2012.

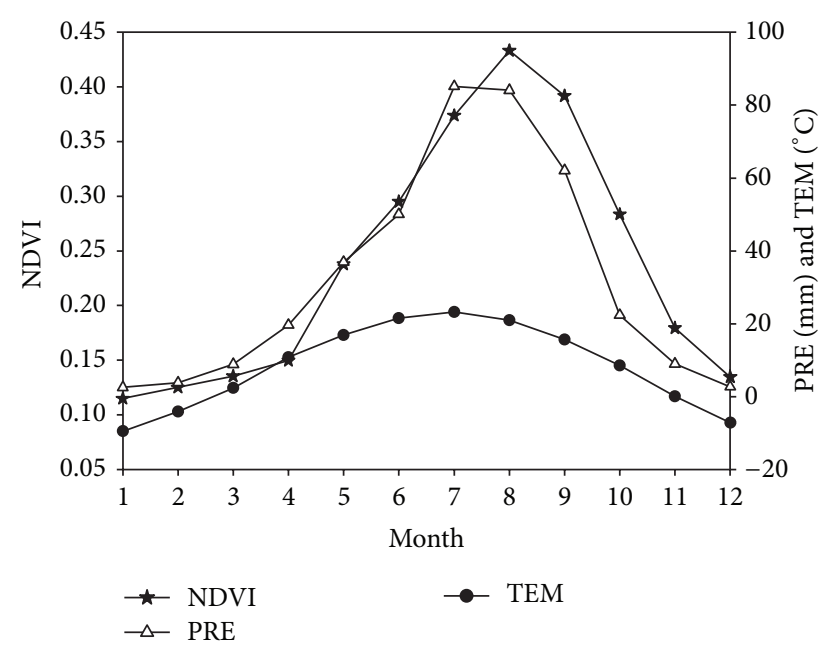

FIGURE 6: The monthly NDVI, precipitation, and temperature on the northern Loess Plateau from 1998 to 2012.

of the year. This lag can be explained by the fact that in this period, the PRE was large and could not be totally used by plants over short time periods. And the time required for the plants to use the water for production was approximately 1 month.

\subsection{Influence of Human Activities on the NDVI}

3.3.1. The Impacts of the "Grain for Green" Program. Climate change was found to be the most important factor influencing the spatial and temporal changes in vegetation coverage. However, human activities are also major driving factors and cannot be neglected. The Loess Plateau is well known for its intensive soil erosion, contributing $90 \%$ of the sediments in the Yellow River [44]. In an attempt to reduce the soil erosion rate, the Chinese government launched the "Grain for Green" program (GGP) in 1999. The goals of this program were to increase forest coverage and mitigate soil erosion by converting agricultural lands on steep slopes to forests and grasslands [45]. Recently, several researchers have examined the effects of the GGP program. For example, Xiao used a variety of satellite data products from MODIS to assess the biophysical consequences of the GGP. He found that the average tree coverage in the plateau substantially increased, and the GGP led to significant increases in the enhanced vegetation index (EVI) and leaf area index (LAI) [23]. Tang et al. analyzed the spatial differences related to land-use change on Loess Plateau region from 1996 to 2005. They noted that farmland areas on the Loess Plateau decreased significantly, while forested areas increased significantly [46].

To further demonstrate the improvements in the vegetation condition on the northern Loess Plateau from 1997 to 2010, we studied the dynamic land-use change in the study area. Table 2 shows that the main land-use types in the study area were grassland, farmland, and forestland, which combined to account for $85.58 \%$ and $84.79 \%$ of the total area of the study region in 1997 and 2010, respectively. Forestland areas increased the most, that is, from $10140.58 \mathrm{~km}^{2}$ in 1997 to $12373.57 \mathrm{~km}^{2}$ in 2010 , with an average annual increase of $159.50 \mathrm{~km}^{2}$. Although grassland areas decreased the most, from $45.80 \%$ of the region in 1997 to $44.04 \%$ in 2010 , the total area of forestland and grassland increased from $54.81 \%$ in 1997 to $55.04 \%$ in 2010. Farmland areas decreased at a rate of $81.38 \mathrm{~km}^{2} / \mathrm{yr}$. These variations in land-use characteristics were similar to the results of Tang et al. [46]. Furthermore, the annual maximum NDVI exhibited a significantly increasing trend for forestland and grassland $(P<0.05)$. It can be 
TABLE 2: Changes in land-cover area on the northern Loess Plateau region between 1997 and 2010.

\begin{tabular}{lcccc}
\hline Land type & Area in $1997\left(\mathrm{~km}^{2}\right)$ & Area ratio in 1997 (\%) & Area in 2010 $\left(\mathrm{km}^{2}\right)$ & Area ratio in 2010 $(\%)$ \\
\hline Farmland & 34604.82 & 30.76 & 33465.49 & 12373.57 \\
Forestland & 10140.58 & 9.01 & 49540.2 & 11.00 \\
Grassland & 51520.69 & 45.80 & 1986.34 & 44.04 \\
Water bodies & 1935.73 & 1.72 & 1942.18 & 1.77 \\
Urban and built-up land & 1549.50 & 1.38 & & 1.73 \\
\hline
\end{tabular}

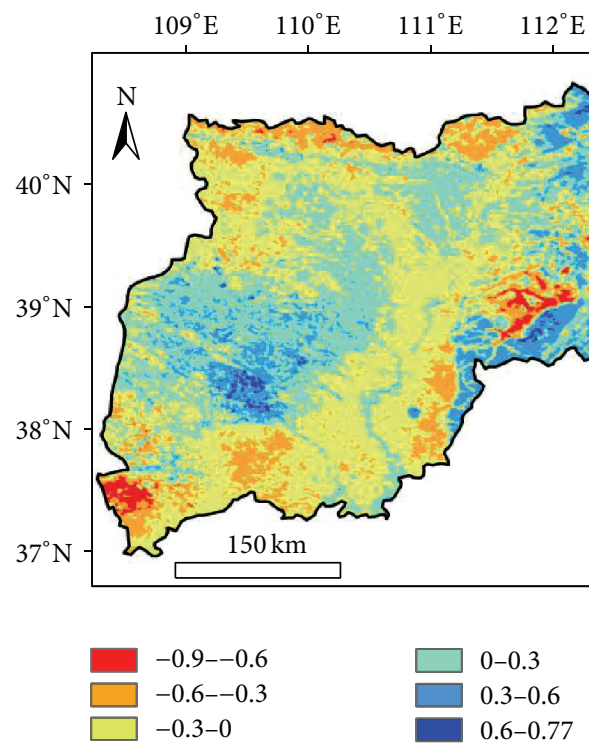

(a)

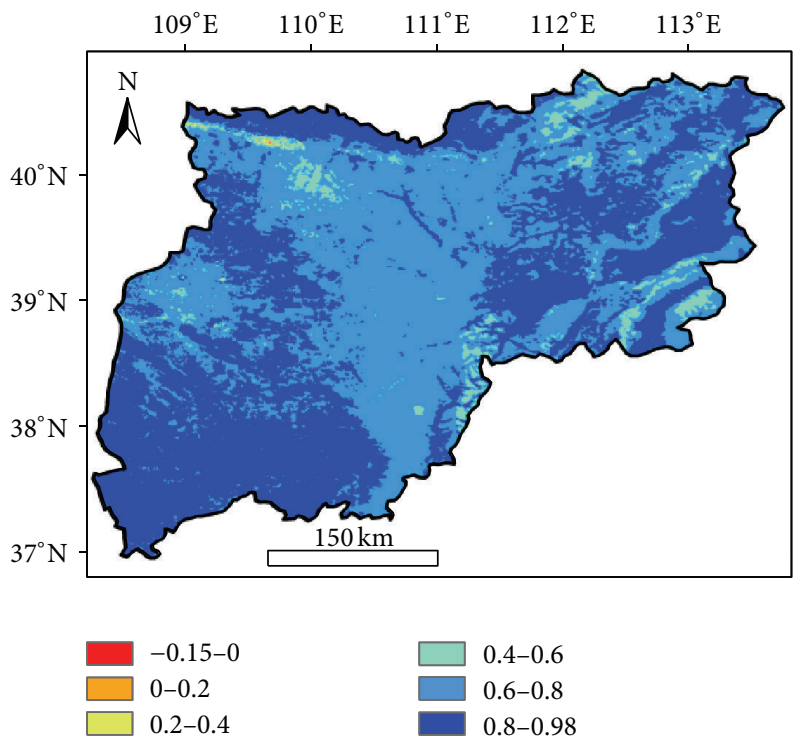

(b)

FIGURE 7: Correlation relationship between the monthly NDVI and monthly (a) mean temperature and (b) precipitation on the northern Loess Plateau from 1998 to 2012.

concluded that the increasing NDVI trend and land-use changes indicate that the GGP was successful over the 15-year study period on the northern Loess Plateau.

Although the farmland areas decreased from 1998 to 2010, its NDVI increased significantly over the 15 -year study period $(P<0.05)$. This change can be explained by agricultural activities, such as the use of fertilizer and pesticides, the construction of water conservation facilities, and intensive agricultural management, which led to increases in grain yields and/or biomass production, thus increasing the NDVI in these areas. The Hetao Plain, which is located on the northern Loess Plateau, is one such example. From 1982 to 2005, the grain yield increased, reaching a steady state in the late 1990s. Simultaneously, the vegetation coverage in this area also increased and was positively correlated with the grain yield [47].

3.3.2. The Impacts of Coal Mining. The NDVI values at the two coal mining bases were lower than those for the entire study area. At Heidaigou, the NDVI was the lowest, especially over the most recent 10 years, which was largely due to massive open-pit mining. During opencast mining, the surface soil layer and vegetation are completely destroyed by mechanical excavation. Moreover, water resources, including groundwater, soil water and surface water, and soil quality are also influenced by coal mining, thus affecting vegetation growth. But it is noting that the NDVI values at the two coal mining bases also increased over the recent 15 years, which was due to mine protection investments and successful environmental treatments. Using the Shenfu-Dongsheng coal mine base as an example, the coal company invested 0.45 yuan per ton of coal for environmental protection. As coal production increases, so does the amount of funds used to protect coal mining areas, which has guaranteed the sustainability and stabilization of greening and environmental treatments and has played an important role in improving vegetation coverage at coal mining bases.

\section{Conclusions}

This study combined SPOT VEGETATION and climatic factor data from 1998 to 2012 to analyze spatial and temporal vegetation variations in the context of climate change. We also explored the potential impacts of human activities on the observed NDVI changes on the northern Loess Plateau. Our conclusions are as follows.

The spatial distribution of the annual maximum NDVI on the northern Loess Plateau exhibited obvious heterogeneity. 
The NDVI gradually decreased from east to west. The annual maximum NDVI was 0.44 , increasing at a rate of 0.09 per decade. The areas where the NDVI significantly increased accounted for $73.6 \%$ of the total area, and severe desertification areas decreased significantly $(P<0.05)$ from $54.7 \%$ in 1999 to $8.9 \%$ in 2012 (a rate of $2.1 \% / y r$ ). This result indicates that the vegetation condition has improved in this area. Although the NDVI values at the two coal mining bases increased over the 15-year study period, they were all lower than the values for the entire study area, which was largely due to massive open-pit mining.

From 1998 to 2012, the temperature significantly decreased at a rate of $-0.61^{\circ} \mathrm{C} / 10 \mathrm{yr}$, while the precipitation slightly increased at a rate of $52 \mathrm{~mm} / 10 \mathrm{yr}$. The precipitation also increased in spring and summer, which promoted vegetation growth and represents one of the major reasons for the increase in the annual NDVI. The correlation with the annual NDVI was stronger for precipitation than temperature, indicating that vegetation is more sensitive to precipitation changes in this area. The NDVI and PRE changed synchronously during the first half of the year, while a 1-month lag time existed between the NDVI and PRE during the last half of the year.

From 1998 to 2012, the total areas of forestland and grassland increased, and the annual maximum NDVI exhibited an increasing trend for these two land-use types $(P<0.05)$, indicating that the GGP was successful over the 15-year study period on the northern Loess Plateau. Although the farmland areas decreased, its NDVI increased significantly over the 15-year study period $(P<0.05)$, which can be explained by positive agricultural activities. Moreover, the NDVI improvements at the two coal mining bases were related to environmental protection investments and successful environmental treatments. Therefore, we conclude that positive human activities were another reason for the vegetation condition improvements.

\section{Conflict of Interests}

The authors declare that there is no conflict of interests regarding the publication of this paper.

\section{Acknowledgments}

This study was supported by the the CAS Action-Plan for Western Development (KZCX2-XB3-13) and Water conservancy science and technology project of Shaanxi Province. The authors also highly appreciated the editor and two anonymous reviewers for their thoughtful comments that were of big help in improving the paper.

\section{References}

[1] J. Peng, Z. Liu, Y. Liu, J. Wu, and Y. Han, "Trend analysis of vegetation dynamics in Qinghai-Tibet Plateau using Hurst Exponent," Ecological Indicators, vol. 14, no. 1, pp. 28-39, 2012.

[2] H. Godínez-Alvarez, J. E. Herrick, M. Mattocks, D. Toledo, and J. van Zee, "Comparison of three vegetation monitoring methods: their relative utility for ecological assessment and monitoring," Ecological Indicators, vol. 9, no. 5, pp. 1001-1008, 2009.

[3] X. W. Chuai, X. J. Huang, W. J. Wang, and G. Bao, "NDVI, temperature and precipitation changes and their relationships with different vegetation types during 1998-2007 in Inner Mongolia, China," International Journal of Climatology, vol. 33, no. 7, pp. 1696-1706, 2013.

[4] S. Piao and J. Fang, "Seasonal changes in vegetation activity in response to climate changes in China between 1982 and 1999," Acta Geographica Sinica, vol. 58, no. 1, pp. 119-125, 2003.

[5] B. Fu, S. Li, X. Yu et al., "Chinese ecosystem research network: progress and perspectives," Ecological Complexity, vol. 7, no. 2, pp. 225-233, 2010.

[6] J. W. Rouse Jr., R. Haas, J. Schell et al., "Monitoring vegetation systems in the Great Plains with ERTS," NASA Special Publication, vol. 351, p. 309, 1974.

[7] C. Li, J. Qi, L. Yang et al., "Regional vegetation dynamics and its response to climate change-a case study in the Tao River Basin in Northwestern China," Environmental Research Letters, vol. 9, no. 12, Article ID 125003, 2014.

[8] J. Fang, S. Piao, J. He, and W. Ma, "Increasing terrestrial vegetation activity in China, 1982-1999," Science in China Series C: Life Sciences, vol. 47, no. 3, pp. 229-240, 2004.

[9] Z. Yin and T. H. Lee Williams, "Obtaining spatial and temporal vegetation data from Landsat MSS and AVHRR/NOAA satellite images for a hydrologic model," Photogrammetric Engineering and Remote Sensing, vol. 63, no. 1, pp. 69-77, 1997.

[10] C. Liu, X. Dong, and Y. Liu, "Changes of NPP and their relationship to climate factors based on the transformation of different scales in Gansu, China," CATENA, vol. 125, pp. 190199, 2015

[11] S. L. Piao, J. Y. Fang, and J. S. He, "Variations in vegetation net primary production in the Qinghai-Xizang Plateau, China, from 1982 to 1999," Climatic Change, vol. 74, no. 1-3, pp. 253-267, 2006.

[12] F. Rembold and F. Maselli, "Estimation of inter-annual crop area variation by the application of spectral angle mapping to low resolution multitemporal NDVI images," Photogrammetric Engineering and Remote Sensing, vol. 72, no. 1, pp. 55-62, 2006.

[13] M. S. Mkhabela, P. Bullock, S. Raj, S. Wang, and Y. Yang, "Crop yield forecasting on the Canadian Prairies using MODIS NDVI data," Agricultural and Forest Meteorology, vol. 151, no. 3, pp. 385-393, 2011.

[14] D.-Y. Gong and P.-J. Shi, "Northern hemispheric NDVI variations associated with large-scale climate indices in spring," International Journal of Remote Sensing, vol. 24, no. 12, pp. 25592566, 2003.

[15] D. A. Walker, H. E. Epstein, G. J. Jia et al., "Phytomass, LAI, and NDVI in northern Alaska: relationships to summer warmth, soil $\mathrm{pH}$, plant functional types, and extrapolation to the circumpolar arctic," Journal of Geophysical Research D: Atmospheres, vol. 108, no. 2, pp. 10-15, 2003.

[16] J. Y. Zhang, W. J. Dong, C. B. Fu, and L. Wu, "The influence of vegetation cover on summer precipitation in China: a statistical analysis of NDVI and climate data," Advances in Atmospheric Sciences, vol. 20, no. 6, pp. 1002-1006, 2003.

[17] R. P. Singh, S. Roy, and F. Kogan, "Vegetation and temperature condition indices from NOAA AVHRR data for drought monitoring over India," International Journal of Remote Sensing, vol. 24, no. 22, pp. 4393-4402, 2003. 
[18] Q. Wang, M. Watanabe, S. Hayashi, and S. Murakami, "Using NOAA AVHRR data to assess flood damage in China," Environmental Monitoring and Assessment, vol. 82, no. 2, pp. 119-148, 2003.

[19] R. B. Myneni, C. D. Keeling, C. J. Tucker, G. Asrar, and R. R. Nemani, "Increased plant growth in the northern high latitudes from 1981 to 1991,” Nature, vol. 386, no. 6626, pp. 698-702, 1997.

[20] A. Kawabata, K. Ichii, and Y. Yamaguchi, "Global monitoring of interannual changes in vegetation activities using NDVI and its relationships to temperature and precipitation," International Journal of Remote Sensing, vol. 22, no. 7, pp. 1377-1382, 2001.

[21] J. Xiao and A. Moody, "Geographical distribution of global greening trends and their climatic correlates: 1982-1998," International Journal of Remote Sensing, vol. 26, no. 11, pp. 2371-2390, 2005.

[22] S. Liang, J. Chen, X. Jin et al., "Regularity of vegetation coverage changes in the Tibetan Plateau over the last 21 years," Advances in Earth Science, vol. 22, no. 1, pp. 33-40, 2007.

[23] J. F. Xiao, "Satellite evidence for significant biophysical consequences of the 'Grain for Green' Program on the Loess Plateau in China," Journal of Geophysical Research: Biogeosciences, vol. 119, no. 12, pp. 2261-2275, 2014.

[24] T. Wang, X. Kou, Y. Xiong, P. Mou, J. Wu, and J. Ge, “Temporal and spatial patterns of NDVI and their relationship to precipitation in the loess plateau of China," International Journal of Remote Sensing, vol. 31, no. 7, pp. 1943-1958, 2010.

[25] M. T. Schnur, H. Xie, and X. Wang, "Estimating root zone soil moisture at distant sites using MODIS NDVI and EVI in a semiarid region of southwestern USA," Ecological Informatics, vol. 5, no. 5, pp. 400-409, 2010.

[26] X. Chen and R. Yu, "Spatial and temporal variations of the vegetation growing season in warm-temperate eastern China during 1982 to 1999," Acta Geographica Sinica, vol. 62, no. 1, pp. 41-51, 2007.

[27] D. C. Sohoulande Djebou, V. P. Singh, and O. W. Frauenfeld, "Vegetation response to precipitation across the aridity gradient of the southwestern United states," Journal of Arid Environments, vol. 115, pp. 35-43, 2015.

[28] W. Thavorntam and N. Tantemsapya, "Vegetation greenness modeling in response to climate change for Northeast Thailand," Journal of Geographical Sciences, vol. 23, no. 6, pp. 10521068, 2013.

[29] R. Cao, W. Jiang, L. Yuan, W. Wang, Z. Lv, and Z. Chen, "Interannual variations in vegetation and their response to climatic factors in the upper catchments of the Yellow River from 2000 to 2010," Journal of Geographical Sciences, vol. 24, no. 6, pp. $963-$ 979, 2014.

[30] X. Liu, J. Zhang, X. Zhu et al., "Spatiotemporal changes in vegetation coverage and its driving factors in the Three-River Headwaters Region during 2000-2011," Journal of Geographical Sciences, vol. 24, no. 2, pp. 288-302, 2014.

[31] J. Wang, P. M. Rich, and K. P. Price, “Temporal responses of NDVI to precipitation and temperature in the central Great Plains, USA," International Journal of Remote Sensing, vol. 24, no. 11, pp. 2345-2364, 2003.

[32] P. A. Schultz and M. S. Halpert, "Global analysis of the relationships among a vegetation index, precipitation and land surface temperature," International Journal of Remote Sensing, vol. 16, no. 15, pp. 2755-2777, 1995.

[33] Y. Liu, X. Wang, M. Guo, H. Tani, N. Matsuoka, and S. Matsumura, "Spatial and temporal relationships among NDVI, climate factors, and land cover changes in Northeast Asia from 1982 to 2009," GIScience \& Remote Sensing, vol. 48, no. 3, pp. 371-393, 2011.

[34] Y. He, X. Guo, P. Dixon, and J. F. Wilmshurst, "NDVI variation and its relation to climate in Canadian ecozones," The Canadian Geographer, vol. 56, no. 4, pp. 492-507, 2012.

[35] G. Tian, X. Shang, J. Li et al., "A strategic study of coal exploitation in Shanxi, Shannxi and Inner Mongolia," Coal Geology of China, vol. 20, no. 3, pp. 1-15, 2008.

[36] B. N. Holben, "Characteristics of maximum-value composite images from temporal AVHRR data," International Journal of Remote Sensing, vol. 7, no. 11, pp. 1417-1434, 1986.

[37] S. Chamaillé-Jammes and H. Fritz, "Precipitation-NDVI relationships in eastern and southern African savannas vary along a precipitation gradient," International Journal of Remote Sensing, vol. 30, no. 13, pp. 3409-3422, 2009.

[38] Y. He, X. Guo, P. Dixon, and J. F. Wilmshurst, "NDVI variation and its relation to climate in Canadian ecozones," Canadian Geographer, vol. 56, no. 4, pp. 492-507, 2012.

[39] M. Lanfredi, R. Lasaponara, T. Simoniello, V. Cuomo, and M. Macchiato, "Multiresolution spatial characterization of land degradation phenomena in southern Italy from 1985 to 1999 using NOAA-AVHRR NDVI data," Geophysical Research Letters, vol. 30, no. 2, 2003.

[40] J. Sun, G. Cheng, W. Li, Y. Sha, and Y. Yang, "On the variation of NDVI with the principal climatic elements in the Tibetan Plateau," Remote Sensing, vol. 5, no. 4, pp. 1894-1911, 2013.

[41] Y. Song and M. Ma, "Study on vegetation cover change in northwest China based on SPOT VEGETATION data," Journal of Desert Research, vol. 27, no. 1, pp. 90-94, 2007.

[42] E. G. Jobbágy, O. E. Sala, and J. M. Paruelo, "Patterns and controls of primary production in the Patagonian steppe: a remote sensing approach," Ecology, vol. 83, no. 2, pp. 307-319, 2002.

[43] S. Piao, A. Mohammat, J. Fang, Q. Cai, and J. Feng, "NDVIbased increase in growth of temperate grasslands and its responses to climate changes in China," Global Environmental Change, vol. 16, no. 4, pp. 340-348, 2006.

[44] M.-E. Ren and Y.-L. Shi, "Sediment discharge of the Yellow River (China) and its effect on the sedimentation of the Bohai and the Yellow Sea," Continental Shelf Research, vol. 6, no. 6, pp. 785-810, 1986.

[45] X. Mu, L. Zhang, T. R. McVicar, B. Chille, and P. Gau, "Analysis of the impact of conservation measures on stream flow regime in catchments of the Loess Plateau, China," Hydrological Processes, vol. 21, no. 16, pp. 2124-2134, 2007.

[46] Q. Tang, Y. Xu, and Y. Liu, "Spatial difference of land use change in Loess Plateau region," Journal of Arid Land Resources and Environment, vol. 24, no. 8, pp. 15-21, 2010.

[47] Z. Xin, J. Xu, and W. Zheng, "The impacts of climate variability and human activities on the change of vegetation coverage on the Loess Plateau," Science China Earth Sciences, vol. 37, no. 11, pp. 1504-1514, 2007. 

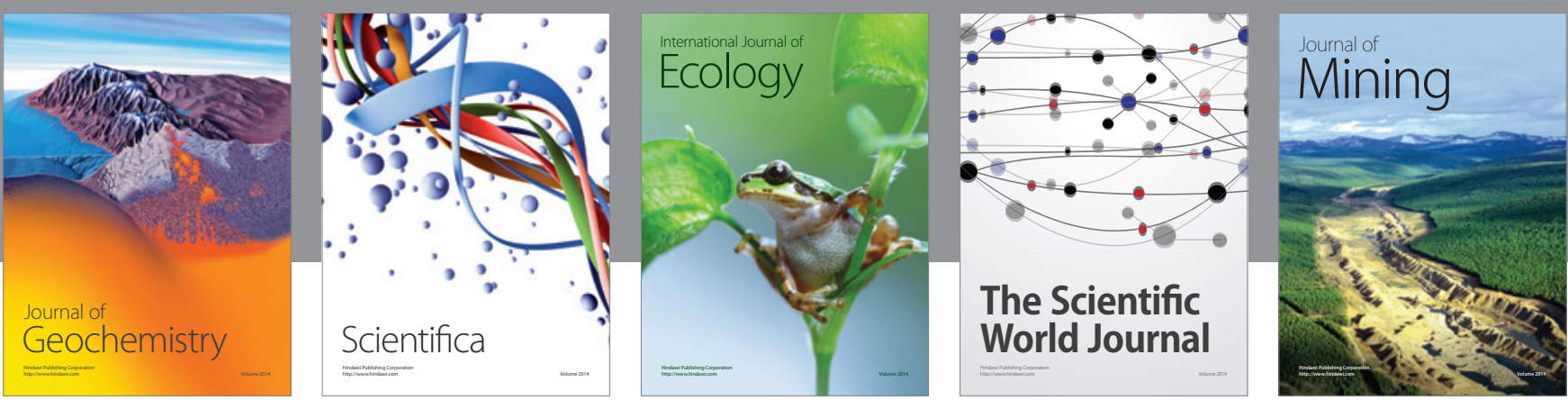

The Scientific World Journal
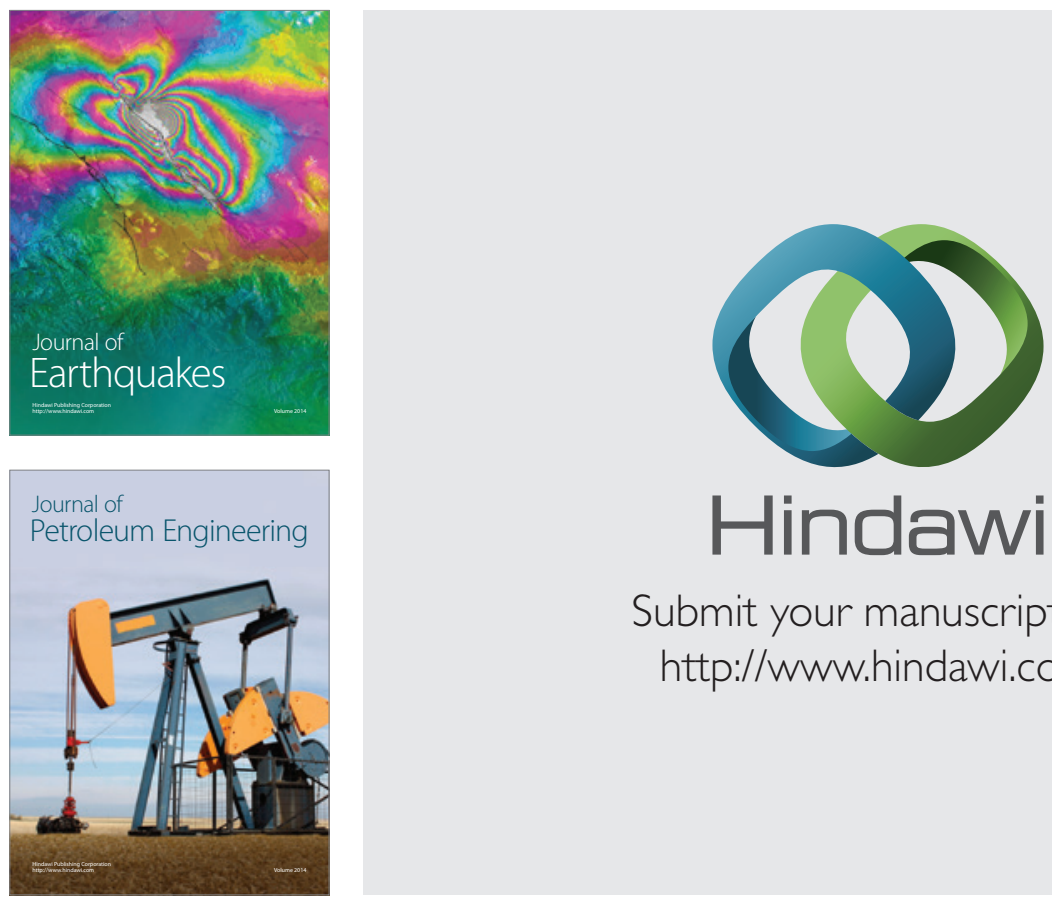

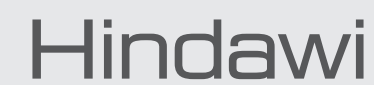

Submit your manuscripts at

http://www.hindawi.com
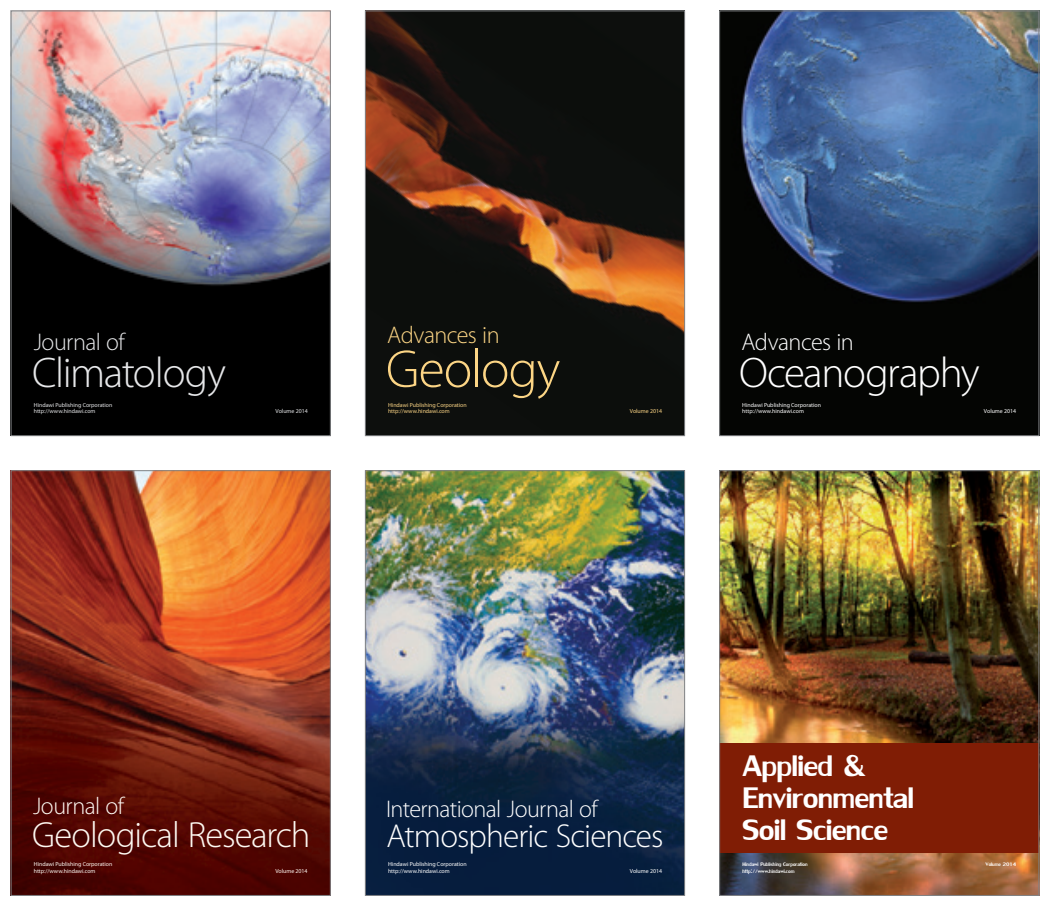
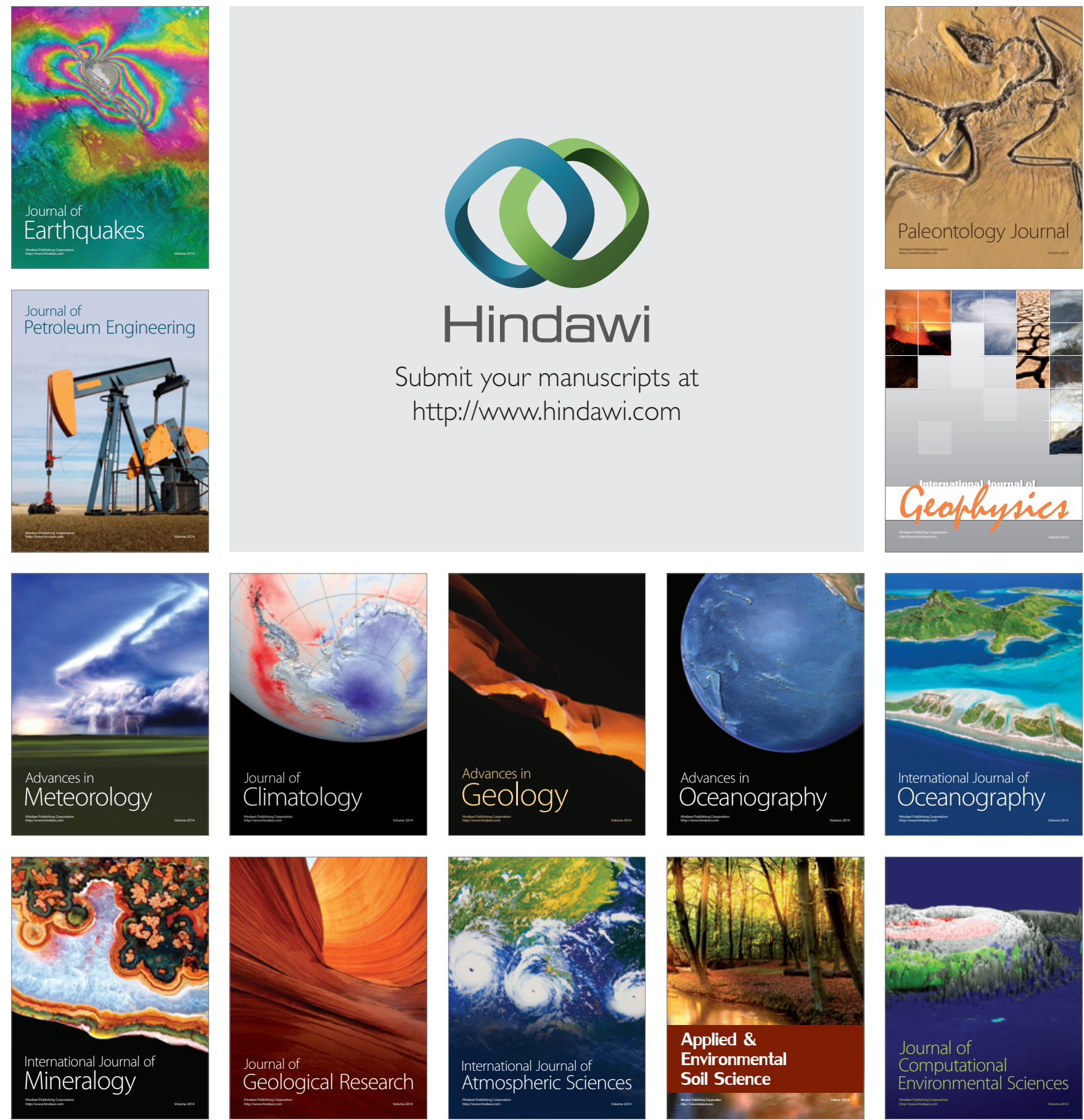